\title{
Research on Blended Teaching Mode Based on Gaoxiaobang Platform
}

\author{
Haoyan Shao ${ }^{1, *}$, Na Qiao ${ }^{1}$, and Xiaohui Zhang ${ }^{2}$ \\ ${ }^{1}$ School of Distance and Continuing Education, Dalian University of Technology \\ ${ }^{2}$ School of Computer and Information Technology, Liaoning Normal University
}

\begin{abstract}
With the gradually deeper development of Higher education informationization and online open educational pattern, blended teaching mode has become a common concern. We practically use Gaoxiaobang course platform to carry out blended teaching mode in the course of Piano art and classics enjoy, and research teaching case to provide reference for blended teaching mode. KeywordsMOOC.Blended teaching mode; Gaoxiaobang course platform; Piano art and classics enjoy
\end{abstract}

\section{Introduction}

With the fast development of network, educational circles are full of teaching mode based on MOOC, and online open educational pattern makes most people of educational field looking forward to use MOOC to replace traditional classroom teaching. But the MOOC itself exists deficiency, and need face-to-face education to supplement. [1]Blended teaching mode combines advantages of traditional classroom teaching and online learning better. To carry out blended learning successfully, we need a network course platform to support learning on which course teacher can share teaching videos they made related with the course content, and upload auxiliary teaching resources to expand students' knowledge range such as PPT、 PDF documents, etc. Teachers hope that the teaching platform has modules to discuss and communicate, and teachers and students can freely express their opinions. Furthermore, teachers hope to observe the students learning process and learning situation to evaluate students comprehensively by the platform. This paper takes the case for Cross-school course of Piano art and classics enjoy in Liaoning province of Dalian University of Technology open course teaching centre, to research blended teaching mode.

\section{MOOC and blended teaching overview}

\subsection{MOOC Overview}

\subsubsection{The Concept of MOOC}

MOOC (Massive open online course) is massive open online courses, and it often referred to as "Mu Ke" in Chinese. Three course providers represented by
Coursera、Udacity and edX provide a platform for the development of MOOC. [2 3] In recent years, universities at home and abroad have joined MOOC, and developed rapidly. MOOC develop so rapidly by reason of the potential of enriched traditional classroom. MOOC meanwhile has many shortages, such as lack of communication between teachers and students and low attendance, etc. Therefore, we should treat MOOC dialectically.

\subsubsection{The Characteristics of MOOC}

MOOC has the following characteristics: (1) massive. Massive means plenty of enrollment and abundant curriculum resource; (2) open. Open means. learning space and learning resource is open in $\mathrm{MOOC}$, and all the courses students interested in can be registered to study; (3) online. All the learning process is done through the internet, such as teacher teaching、students learning 、 teacher-students/ student-students interaction 、 homework finishing and homework correcting; (4)course. Course represents that the content provided by MOOC is complete course, and it is a progression that the $\mathrm{MOOC}$ relatives to open education resources. Open education resources provide many excellent resources, but all the learning process is incomplete because of the lack of teachers' guidance and companion's mutual help, therefore excellent educational resources are failed to make full use. Then the MOOC appears in the form of course with specific classes begin time and classes over time, and it can improve the finishing rate and the use value of education resources greatly.

\subsection{Blended Teaching Overview}

* Corresponding author: network4@,dlut.edu.cn 
Blended teaching is not only a kind of teaching form, is also a kind of teaching strategy, and the definition of it at home and abroad experiences from broad to narrow.

In a broad sense, blend in blended teaching includes: blend of learning theory、 blend of learning resources 、 blend of learning resources 、blend of learning style and blend of learning style 。[4 6]This explanation led to confusion of the blended teaching concept, because of the excessive contents it contains, and blended teaching lost the significance to be a independent concept due to this definition.

In narrow sense, with the constantly understanding and in-depth research of blended teaching theory, the definition of blended teaching has gradually been refined internationally, and the combination of face to face traditional teaching mode and blended teaching mode has been focused on. Bonk and Graham have defined blended learning in the "blended learning handbook", they believe that blended learning is a new learning form which gathers the feature of Face-to-face teaching and many technology medium teaching. India NIIT Company describes blended learning as a new learning form including entity classroom teaching, online learning and learners' active learning in the book of "blended learning white paper".

Blended teaching is a new teaching mode which combines the advantages of traditional classroom teaching and online learning by the view of teaching designers, complement each other to promote the teaching goal better achieved. Blended teaching combines traditional classroom teaching and the latest information media means on the teaching method, adopts online and offline form in the teaching form, takes full advantage of teachers' domination and students' learning autonomy in the relationship between teachers and students. It establishes democracy and equality relationship on the relationship between teachers and students, and adopts the evaluation method which combines formative assessment with summative assessment.

\section{Blended teaching mode of Piano art and classics enjoy based on Gaoxiaobang platform}

\subsection{Introduce of Cross-school course in Liaoning province}

Cross-school credit study project of Piano art and classics enjoy is sponsored Education department of Liaoning province which is established in the form of educational reform project. Cross-school credit study course carries through teaching for full-time recruitment undergraduate level student, and course credit is recognized together by office of academic affairs and teaching teacher who use the course v video building teacher, the final result is depended on which office of academic affairs have recognized and published Crossschool credit study course is different from traditional classroom teaching mode, and newly increase a medium of network platform on the basis of the interaction between teachers and students of traditional teaching. The teaching of cross-school credit study course is a blended teaching mode based on online education, hope to change the deficiency existing in the traditional classroom teaching which mainly includes lack of teaching content novelty、 teacher's guidance after class and learning resources.

The exploration of blended teaching mode on Gaoxiaobang course platform is divided into three types, as shown in the table 1 .

Table 1. The exploration of three types of blended teaching mode on Gaoxiaobang course platform

\begin{tabular}{|c|c|c|c|c|}
\hline $\begin{array}{l}\text { Teaching } \\
\text { Mode }\end{array}$ & Students Task & Teacher in Class & $\begin{array}{c}\text { Video Building } \\
\text { Teacher }\end{array}$ & Characteristic \\
\hline $\begin{array}{l}\text { Flipped } \\
\text { Classroom }\end{array}$ & $\begin{array}{l}\text { 1、 Complete knowledge } \\
\text { study at home } \\
\text { 2、 teacher-students } \\
\text { student-students } \\
\text { interaction in classroom }\end{array}$ & $\begin{array}{l}\text { 1、 teacher-student } \\
\text { interaction, question } \\
\text { answer and discussion } \\
\text { in classroom }\end{array}$ & $\begin{array}{l}\text { face to face teaching } \\
\text { teacher is video } \\
\text { building teacher }\end{array}$ & $\begin{array}{l}\text { Grading assignment is } \\
\text { accomplished by video building } \\
\text { teacher. Can make up the problem } \\
\text { of weakness of teaching staff in } \\
\text { some subjects in universities. }\end{array}$ \\
\hline $\begin{array}{l}\text { Half-flipped } \\
\text { Classroom }\end{array}$ & $\begin{array}{l}\text { 1、 Complete knowledge } \\
\text { study at home } \\
\text { 2、 listen to the teaching } \\
\text { content not existed in } \\
\text { class }\end{array}$ & $\begin{array}{l}\text { 1、 add the missing } \\
\text { teaching content to } \\
\text { video courseware } \\
\text { 2、 teacher-students } \\
\text { interaction in } \\
\text { classroom }\end{array}$ & $\begin{array}{l}\text { face to face teaching } \\
\text { teacher is the teacher } \\
\text { of the school which } \\
\text { use the course }\end{array}$ & $\begin{array}{l}\text { Grading assignment is } \\
\text { accomplished by the teacher of the } \\
\text { school which use the course }\end{array}$ \\
\hline $\begin{array}{l}\text { complete } \\
\text { auxiliary }\end{array}$ & $\begin{array}{l}\text { 1、 Normal classroom } \\
\text { listening } \\
\text { 2、 use video to } \\
\text { supplement or revision } \\
\text { offline }\end{array}$ & $\begin{array}{l}\text { Normal classroom } \\
\text { teaching }\end{array}$ & $\begin{array}{l}\text { face to face teaching } \\
\text { teacher and video } \\
\text { building teacher is } \\
\text { the same person or } \\
\text { from the same school }\end{array}$ & $\begin{array}{l}\text { Grading assignment is } \\
\text { accomplished by teaching teacher }\end{array}$ \\
\hline
\end{tabular}




\subsection{Introduce of Gaoxiaobang course platform}

Arising of MOOC 、 micro-Course and flipped Classroom is impacting traditional education. The development of online education has become the world trend. In continuing education, the $\mathrm{MOOC}$ can be quality-oriented education, and it can also be applied in curricula education. In order to enhance open course resource construction and education work, promote quality education teaching resources sharing, use information technology to promote the teaching level, promote teaching reform and improve the quality of teaching, Dalian University of Technology founds open course teaching centre in October 2013 to enhance open course resource construction, and school of distance and continuing education takes charge of the centre' specific operations.

With Dalian University of Technology open course teaching centre work being carried out, a platform named Gaoxiaobang generates under the deployment of the college.

Open course teaching work takes Gaoxiaobang course platform as a online education medium, professional teachers for guidance, unite colleges and universities teacher to carry out teaching and explore all kinds of new type of teaching mode together. Figure 1 is Gaoxiaobang course platform login page.

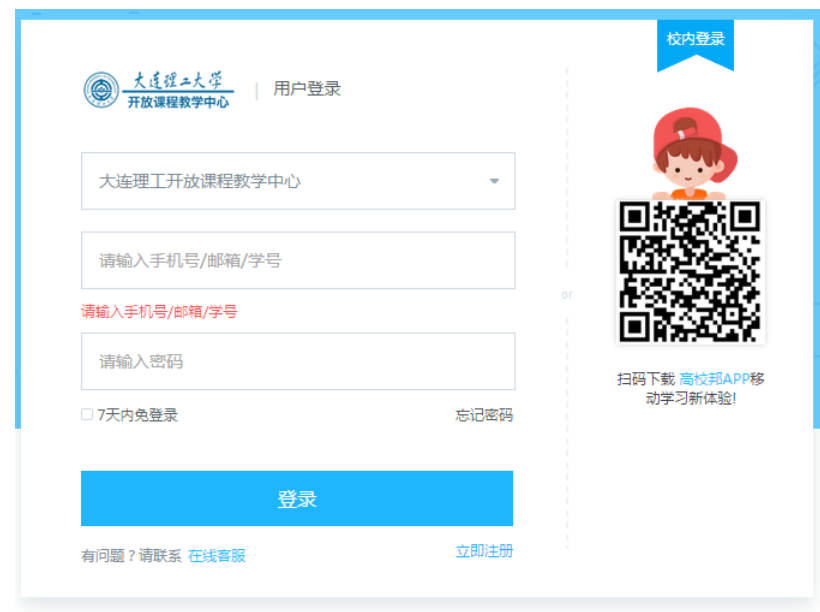

Powered by 高校郝

Fig. 1.Gaoxiaobang course platform login page.

Gaoxiaobang course platform can scan code to download mobile phone APP for mobile learning, and it helps the students make full use of fragmentary time, break through space constraints, and learn the course at any time and any place. It is easy to obtain and has flexible schedules, so the students are inspired to participate in courses actively.

Gaoxiaobang course platform is the medium of network teaching, and teachers and students complete course teaching and learning on it. It has three function modules after logging in the platform, and they are courses square, my study and administrators entrance. The courses square collects 282 high-quality teaching course resources including 50 Liaoning province classic shared classes,112 Liaoning province Cross-school credit study course, 11 Graduate student course,6 undergraduate course.

\subsection{Blended teaching mode practice of Piano art and classics enjoy based on Gaoxiaobang course platform}

Since the spring of 2015 , the exploration of blended teaching mode of Cross-school course of Piano art and classics enjoy in Liaoning province is carried out. The platform invites teaching team of HuangCen teacher from Northeastern University recording video and using the related teaching resources they provided, and Dongbei University of Finance and Economics has carried out blended teaching of that course in the mode of flipped classroom for teaching attempt.

According to the requirement of the teacher given course, Gaoxiaobang course platform realizes all the traditional classroom teaching link, including video of classroom teaching, homework assignment, student work submission, student work review, the interaction between teachers and students in the teaching process, and final examination results generated and export.

The course of Gaoxiaobang platform is build by remedial teacher, and platform interface of remedial teacher as shown in figure 2 . The remedial teacher enters into by administrators entrance, and starts a new course construction from clicking on course creation, then add the content course teaching needs of video,PPT, homework, tests, course introduction, teacher information to the platform. The teacher issues the course after finishing the course construction, then builds new class and adjusts the related content of teaching and examination according to the requirements of different semester. The course of piano art and classics enjoy has rich teaching resources, and the remedial teacher build course and maintain platform, meanwhile the video production teacher HuangCen carries out face to face teaching to the class of Dongbei University of Finance and Economics which uses the platform course. She also interacts with students, course answering for students, carries out the discussion, and assigns homework.

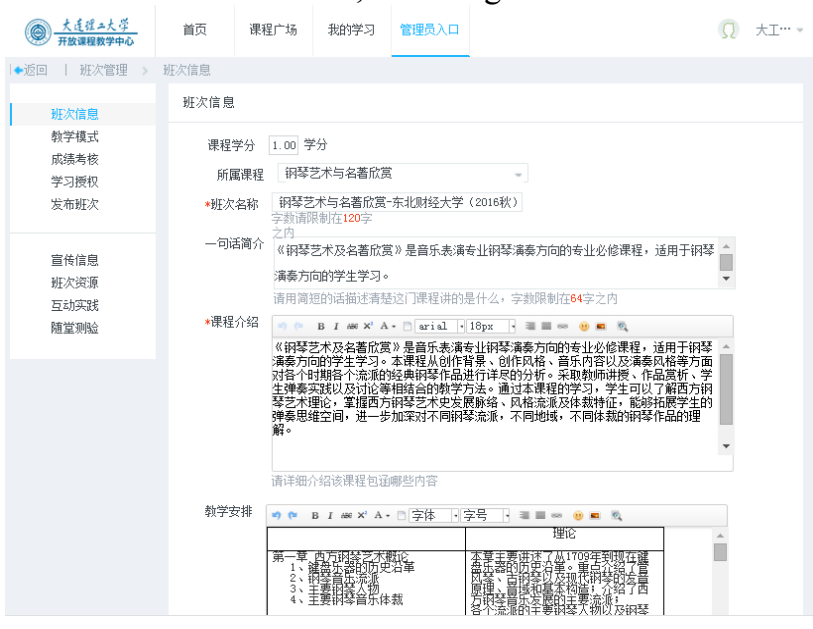

Fig. 2.Gaoxiaobang platform interface of remedial teacher.

Corresponding author: network4@dlut.edu.cn 
The remedial teachers get involved in the capacity of platform technical support and Course guidance teachers in the whole teaching process, help the teaching teacher strengthen the teaching management by multi-channel communication and supervise with the teachers and student. The remedial teachers' work task is shown in figure 3 .

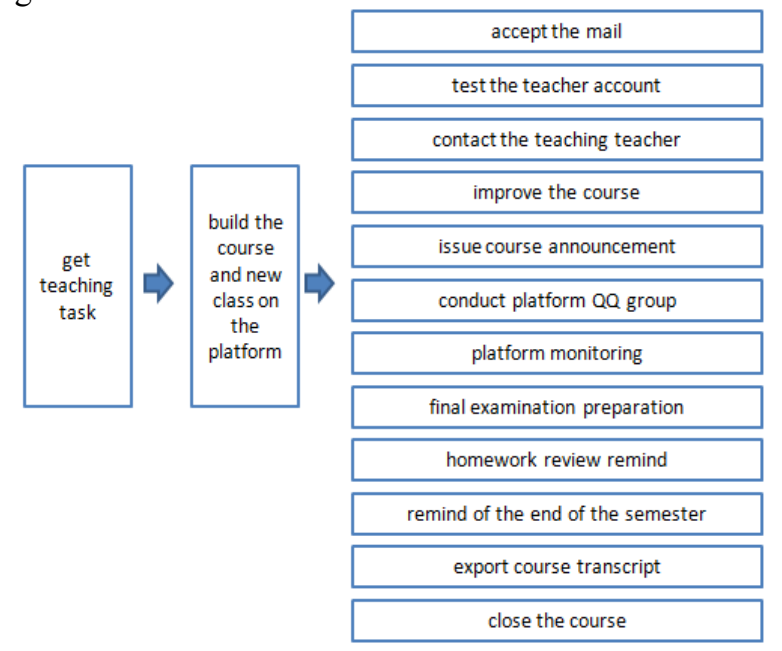

Fig. 3.Gaoxiaobang course platform remedial teacher work flow diagram.

The course examination form is composed of video, homework, tests, discussion, examination five parts according to the percentage composition, after the communication with the teaching teacher, the course final examination form percentage composition is: platform video record $20 \%$, platform test $20 \%$, classroom test $40 \%$, furthermore, homework and discussion are used as self-test assisted learning which are not count to the final record. In the final stage, the remedial teacher derives course transcript from the platform, and deletes the list which is not count to the final record, then compiles course transcript to the teaching teacher.

\section{Blended teaching mode practice and the analysis result}

We carry out the blended teaching mode practice of Piano art and classics enjoy in undergraduate students of Dongbei University of Finance and Economics, and have successfully completed three semesters teaching task. In order to understand student perceptions of blended teaching mode, we carry out questionnaires and interviews to the students of three semesters, and the interviews mainly get through network, QQ chat, E-mail and other forms.

The results show that the blended teaching mode has great effect on improving students' interest and teaching effect.

(1) Most of the students said they would like to study on Gaoxiaobang course platform, and blended teaching has made up for the inadequacy of traditional classroom teaching mode.

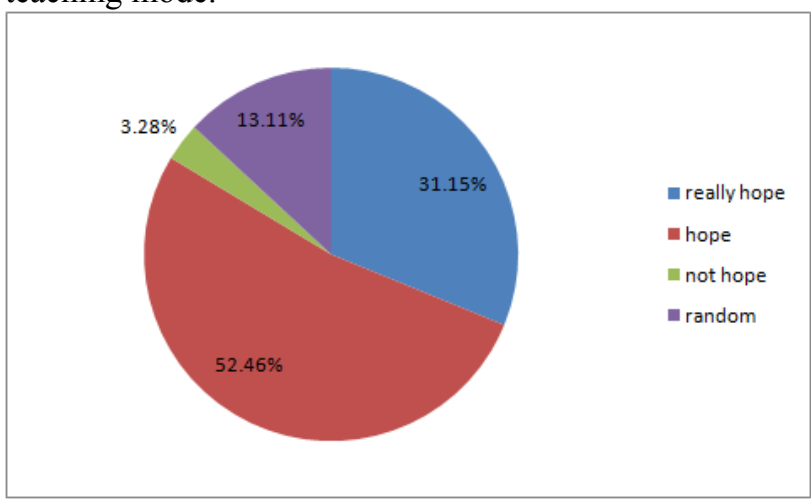

Fig. 4. Whether students hope to study by this mode.

(2) Students said, the diversification of teaching forms increases the students' interest in learning piano art and classic appreciation course, more teaching resources and expand resources on the platform are used to facilitate students' learning and improve the students' classroom participation.

(3) Students also said that the teaching mode expands the autonomous learning space, and their mastery of knowledge level has improved significantly by specific learning according to their knowledge.

(4) Many students said that this mode increased their interaction with the teacher and the students communicate more frequently, and they present original ideas and opinions broaden their thinking in the discussion on the platform. The course learning opens the test limits, and better explores the course content.

At the same time, the writer also gathers the defects in the blended learning of teachers' and students' feedback in the process of interviews, the content is as follows:

Table 2. The main deficiencies and suggestions for improvement of blended teaching mode get in the interviews

\begin{tabular}{|c|l|l|}
\hline & \multicolumn{1}{|c|}{ Problems } & \multicolumn{1}{c|}{ Improvement Suggestions } \\
\hline \multirow{5}{*}{ teacher } & $\begin{array}{l}\text { (1) platform operation is not enough } \\
\text { skillful } \\
\text { (2) teaching practice increase teachers' } \\
\text { workload } \\
\text { (3) homework sets weeks ahead, } \\
\text { individual students can't keep up with the } \\
\text { rhythm. }\end{array}$ & $\begin{array}{l}\text { (1) compile platform operation facilitation manual, teachers and } \\
\text { students are more easy to master } \\
\text { (2) students to do voluntary teaching assistant, set mutual evaluation } \\
\text { of homework, reduce homework marking workload. } \\
\text { (3) extend the effective time of network learning resources and } \\
\text { homework, convenient the teachers and students. }\end{array}$ \\
\hline student & $\begin{array}{l}\text { (1) time to complete the task is limited } \\
\text { (2) some students' learning efficiency is } \\
\text { low, and not willing to try new things. }\end{array}$ & $\begin{array}{l}\text { (1) the teacher should understand the idea of students actively and } \\
\text { change the teaching design any time, then select the most suitable } \\
\text { teaching design for students' development. }\end{array}$ \\
\hline
\end{tabular}


(3) individual module on platform difficult to use, password forget, network problems, etc.
(2) Teachers increase humanistic care to students.

(3) further improve the platform function module, make the interface more friendly.

\section{Conclusions}

Blended teaching ensures that students get systematic knowledge in the traditional classroom, on the basis of advantages of teacher guiding role and good study atmosphere, the learners can learn any knowledge in any time and any place with the infinite extension of time and space, and it satisfies the learners' desire for learning. [7 8]The practice of blended teaching mode of Piano art and classics enjoy based on Gaoxiaobang course platform concludes that it has a great help to improve the teaching quality and promote students' individual development. It is a successful attempt that blended teaching mode applies to Piano art and classics enjoy course teaching, and blended teaching mode based on Gaoxiaobang course platform will play a greater role in schools teaching of various levels while the platform function further improved and the network education resources increased.

\section{References}

1. Ping Wang, New Development and Application of Massive Open Online Course:From CMOOC to $\mathrm{x}$ MOOC $[\mathrm{J}]$. Modern Distance Education Research,2013,(3):56-62.
2. Zaihong He. Teaching Research of C lLanguage and Program Design Course Based on Blended Learning[D]. Changsha: Hunan University,2008,(5),15.

3. Li Yang,Dongsheng Zhao, Research of Blended Learning Based on Moodle Platform [J]. Journal of Capital Normal University(Natural Science) ,2010,(1):6-9.

4. Jide Wang,Yingying Feng.Ying Wang. Cold Think behind the Hot MOOC[J]. Education research, 2014, 9.

5. Kekang He, Look at the New Development of Education Technology Theory from Blended Learning[J]. E-education Research, 2003(3): 610.

6. Apostolos,K., Rebecca J. Hogue. How to Succeed in a MOOC- Massive Online Open Course.Learning Solutions Magazine, October 8,2012.

7. Laura Pappand. The year of the MOOC. The New York Times. November 2, 2012.

8. Laura Pappand. The year of the MOOC. The New York Times. November 2, 2012. 